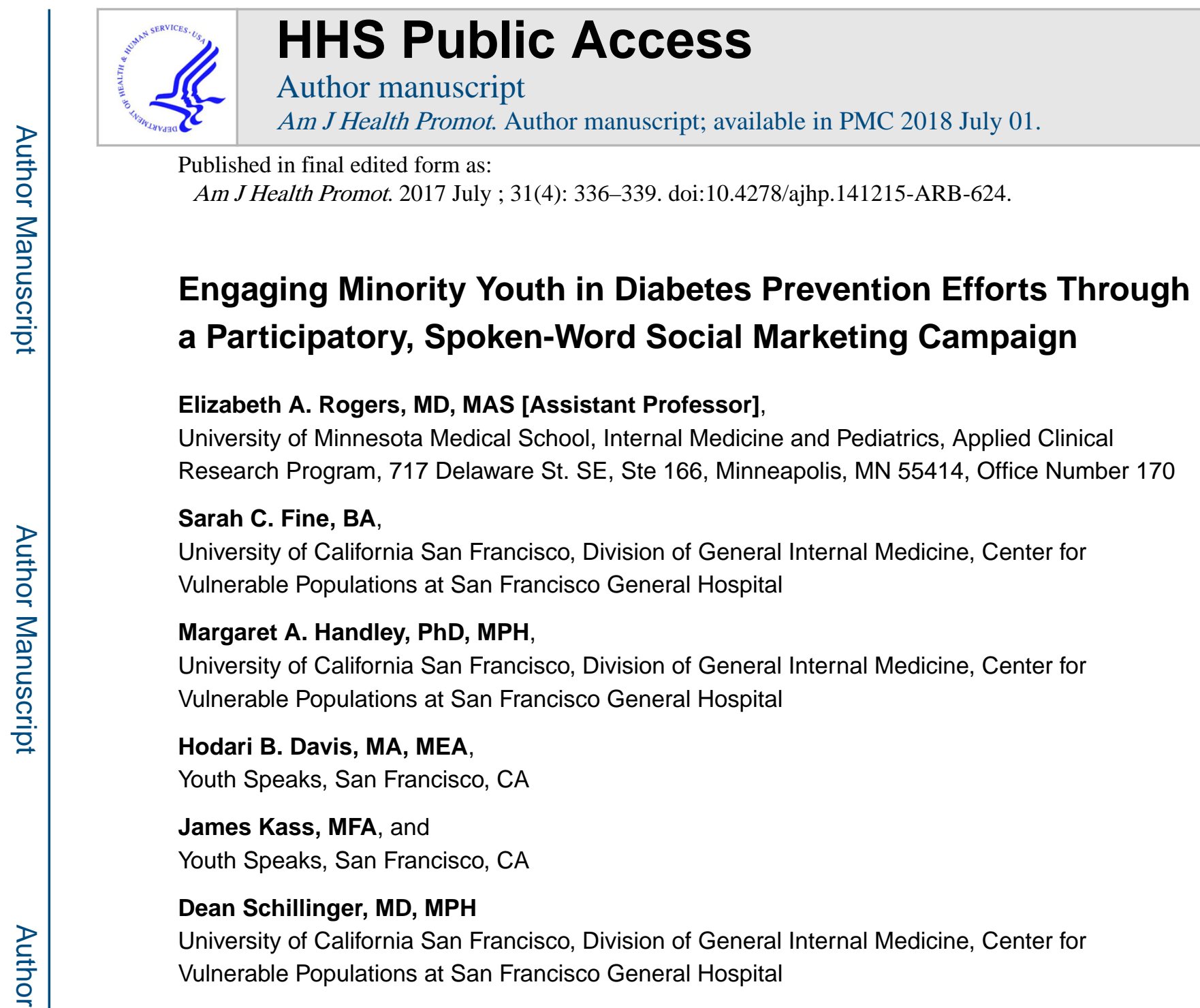

\title{
Purpose
}

The prevalence of type 2 diabetes (T2DM) in youth has increased alarmingly and with widening ethnic disparities. ${ }^{1}$ Among youth aged 12-19 years, 23\% had prediabetes or diabetes in 2008, compared to only $9 \%$ eight years prior. ${ }^{2}$ For $15-19$ year-olds with diabetes in 2009 , T2DM accounted for only $5.5 \%$ of cases for whites, but ranged from $38-80 \%$ in minority groups. ${ }^{3}$

Many T2DM prevention interventions focus on individual behaviors. ${ }^{4-6}$ However, to improve population health, strategies targeting socio-environmental risks are needed, ${ }^{7}$ such as those contributing to success in tobacco control. ${ }^{8}$ One construct stemming from this idea is public health literacy, defined as "the degree to which individuals and groups can obtain, process, understand, evaluate, and act upon information needed to make public health decisions that benefit the community."

Here we evaluate a campaign to increase public health literacy about T2DM risk. Developed through an academic-community partnership, The Bigger Picture combines social 
marketing's focus on targeted health-promoting ideas ${ }^{10}$ with entertainment education's process of designing messages to entertain and educate ${ }^{11}$ for the purposes of increasing knowledge and shifting attitudes among low-income and minority youth - the populations at highest risk of developing T2DM.

\section{Campaign Creation}

The campaign's development is described elsewhere. ${ }^{12}$ Briefly, health professionals from UCSF's Center for Vulnerable Populations (CVP) and staff from Youth Speaks, a youth arts organization, conducted 7 writing workshops over 3 years for 40 youth poets. The CVP team provided information about T2DM, focusing on community-level factors. Poets "re-storied" this information into reflective spoken-word narratives and selected 21 to be professionally produced as video public service announcements (PSAs). Two PSAs were created in English and Spanish. Themes included the association of T2DM with the built environment, advertisements targeting minority youth, sugar addiction, food insecurity, and racial and socioeconomic disparities.

The Bigger Picture team built a campaign website (www.thebiggerpicture.org) in English and Spanish to deliver T2DM information, PSAs, and a downloadable toolkit and workshop book for educators. The team also developed a Facebook page (www.facebook.com/ thebiggerpicturecampaign) and Twitter account (https://twitter.com/BigPicCampaign).

\section{Methods}

Design

We conducted a non-experimental dissemination evaluation of the web-based platform and high school assemblies. The UCSF Committee on Human Research deemed this study exempt.

\section{Sample}

Assemblies were conducted in San Francisco Bay Area schools over 6 months in 2013. At each, a sample of up to 90 high school students used audience response systems ("clickers") to give demographics and respond to 3 questions embedded in the presentation's beginning and end.

\section{Measures}

Evaluation of the campaign's impact focused on the first three dimensions of the RE-AIM framework: reach, effectiveness, and adoption. ${ }^{13}$ Reach was assessed using Web analytic data for the online campaign components, state-reported data for participating schools, and student self-reported demographics collected during school visits. Effectiveness was measured through assembly pre-post questions assessing short-term change in knowledge and attitudes (see Appendix ${ }^{14}$ ). Adoption was assessed by identifying public health or community groups using or endorsing the campaign. 


\section{Intervention}

The team collaborated with school districts and other youth and health stakeholders to (1) promote The Bigger Picture through online venues, at regional public health and medical conferences, and during community activities; and to (2) deliver a one-hour school assembly incorporating T2DM statistics, live poet performances, and video PSAs using a standard script, finalized after 2 pilot school visits.

\section{Analysis}

Descriptive data are presented as counts and proportions. Short-term changes in knowledge and attitudes were assessed by collapsing and dichotomizing pre-post responses ${ }^{14}$ and using McNemar's chi-square test and a mixed model (adjusted for individual student demographics, Table), accounting for clustering at the school level.

\section{Results}

Reach

As of June 2015, the website's educator toolkit and workshop book were downloaded 890 and 1,812 times, respectively; the web-based video PSAs were viewed 1,049,187 times; the Facebook page had 1,388 "likes"; and the Twitter account had 874 followers. For comparison, a systematic review of social networking sites for sexual health promotion demonstrated a median of 327 and 565 users for Facebook and Twitter, respectively. ${ }^{15}$ The assemblies reached the target audience -2460 students, the majority from minority groups (Table).

\section{Effectiveness}

Student knowledge and attitudes about T2DM risk shifted favorably during assemblies (Figure). Students who recognized environmental causes of T2DM increased from 34\% to $83 \%$. Those who "cared a lot" about preventing T2DM increased from $29 \%$ to $59 \%$.

\section{Adoption}

San Francisco and Alameda Counties' Departments of Public Health supported the creation of four PSAs to augment their "Rethink Your Drink" health education campaigns. Both health departments as well as Sonoma County's partnered with UCSF and the American Heart Association (among others) to create the "Open Truth Campaign" which uses The Bigger Picture messaging to educate about the health consequences of sugary drinks and highlights industry's marketing to youth of color. The PSAs have been recognized by San Francisco's "Food Farms and Film Festival" and by Upworthy.com. Team members gave an invited presentation at the 2013 Institute of Medicine Round Table on Health Literacy, presented at the 2014 Center for Science in the Public Interest's National Soda Summit, and were awarded an APHA Spirit of 1848 award linking health to social justice. 


\section{Discussion}

\section{Summary}

The Bigger Picture campaign employs a youth participatory strategy within a public health literacy framework to disseminate information about the socio-environmental contributors to T2DM risk. Built around PSAs created by youth poets from the target population, the campaign has successfully reached high-risk adolescents through school assemblies and positively affected short-term knowledge and attitudes about T2DM prevention. Web-based materials and social media venues offer potential to extend this reach. The campaign has been adopted by public health entities and recognized nationally by the health community.

\section{Limitations}

Limitations of this evaluation include the potential for youth responders to be influenced by social desirability, the short-term nature of the assembly evaluation, and the lack of a comparison group. However, the magnitude of pre-post change is compelling. Challenges include measuring behavior to assess transition from change in attitude to concrete action, and how to best promote youth's civic engagement around health justice, since concrete action to change the built environment is the ultimate goal of raising awareness through this campaign.

\section{Significance}

The youth poets' talent and commitment to social justice led to fresh and engaging PSA content unique in the diabetes health communication landscape. The collaboration with Shape $U p S F$ provides a promising template for broader public health dissemination, and demonstrates that the campaign's public health literacy framework is relevant to stakeholders. The campaign holds potential for increasing content and expanding reach, and presents hopes for fomenting community-level change through youth engagement.

\section{References}

1. Mayer-Davis EJ, Bell RA, Dabelea D, et al. The many faces of diabetes in American youth: Type 1 and type 2 diabetes in five race and ethnic populations: The SEARCH for diabetes in youth study. Diabetes Care. 2009; 32(Suppl 2):S99-S101. [PubMed: 19246580]

2. May AL, Kuklina EV, Yoon PW. Prevalence of cardiovascular disease risk factors among US adolescents, 1999-2008. Pediatrics. 2012; 129(6):1035-1041. [PubMed: 22614778]

3. Pettitt DJ, Talton J, Dabelea D, et al. Prevalence of diabetes in U.S. youth in 2009: The SEARCH for diabetes in youth study. Diabetes Care. 2014; 37(2):402-408. [PubMed: 24041677]

4. Siegrist M, Hanssen H, Lammel C, Haller B, Halle M. A cluster randomised school-based lifestyle intervention programme for the prevention of childhood obesity and related early cardiovascular disease (JuvenTUM 3). BMC Public Health. 2011; 11 258-2458-11-258.

5. Hofsteenge GH, Chinapaw MJ, Weijs PJ, van Tulder MW, Delemarre-van de Waal HA. Go4it; study design of a randomised controlled trial and economic evaluation of a multidisciplinary group intervention for obese adolescents for prevention of diabetes mellitus type 2. BMC Public Health. 2008; 8 410-2458-8-410.

6. Hirst K, Baranowski T, et al. HEALTHY Study Group. HEALTHY study rationale, design and methods: Moderating risk of type 2 diabetes in multi-ethnic middle school students. Int J Obes (Lond). 2009; 33(Suppl 4):S4-S20. [PubMed: 19623188] 
7. Ockene JK, Edgerton EA, Teutsch SM, et al. Integrating evidence-based clinical and community strategies to improve health. Am J Prev Med. 2007; 32(3):244-252. [PubMed: 17296474]

8. Klein JD, Dietz W. Childhood obesity: The new tobacco. Health Affairs. 2010; 29(3):388-392. [PubMed: 20194977]

9. Freedman DA, Bess KD, Tucker HA, Boyd DL, Tuchman AM, Wallston KA. Public health literacy defined. Am J Prev Med. 2009; 36(5):446-451. [PubMed: 19362698]

10. Lefebvre RC, Flora JA. Social marketing and public health intervention. Health Educ Q. 1988; 15(3):299-315. [PubMed: 3056876]

11. Singhal, A., Rogers, EM. Entertainment-education: A communication strategy for social change. Mahwah, N.J: L. Erlbaum Associates; 1999.

12. Rogers EA, Fine S, Handley MA, Davis H, Kass J, Schillinger D. Development and early implementation of The Bigger Picture, a youth-targeted public health literacy campaign to prevent type 2 diabetes. J Health Commun. 2014; 19(Suppl 2):144-160. [PubMed: 25315590]

13. Glasgow RE, Vogt TM, Boles SM. Evaluating the public health impact of health promotion interventions: The RE-AIM framework. Am J Public Health. 1999; 89(9):1322-1327. [PubMed: 10474547]

14. Rogers EA, Fine S, Handley M, Davis H, Kass J, Schillinger D. Appendix for AJHP applied research brief. UCSF CHARM website. 2015 Jun 25. [Accessed June 25, 2015] http:// charm.ucsf.edu/ajhp-applied-research-brief-appendix.

15. Gold J, Pedrana AE, Sacks-Davis R, et al. A systematic examination of the use of online social networking sites for sexual health promotion. BMC Public Health. 2011; 11 583-2458-11-583. 


\section{So What?}

What is already known on this topic?

Many T2DM prevention interventions focus on individual behaviors. To contribute to a holistic health literacy strategy, health communication targeting socio-environmental risks are needed.

\section{What does this article add?}

This article outlines the evaluation of The Bigger Picture campaign which aims to increase public health literacy about preventing T2DM through educating youth about socio-environmental risks. The evaluation demonstrates reach, efficacy, and adoption of the campaign.

\section{What are the implications for health promotion practice or research?}

Because this campaign is web-based, it has potential for dissemination to a broad audience. By providing health information from a socio-ecologic perspective, this campaign holds potential for understanding whether framing T2DM risk as a social justice issue can foment motivation for change among adolescents. 


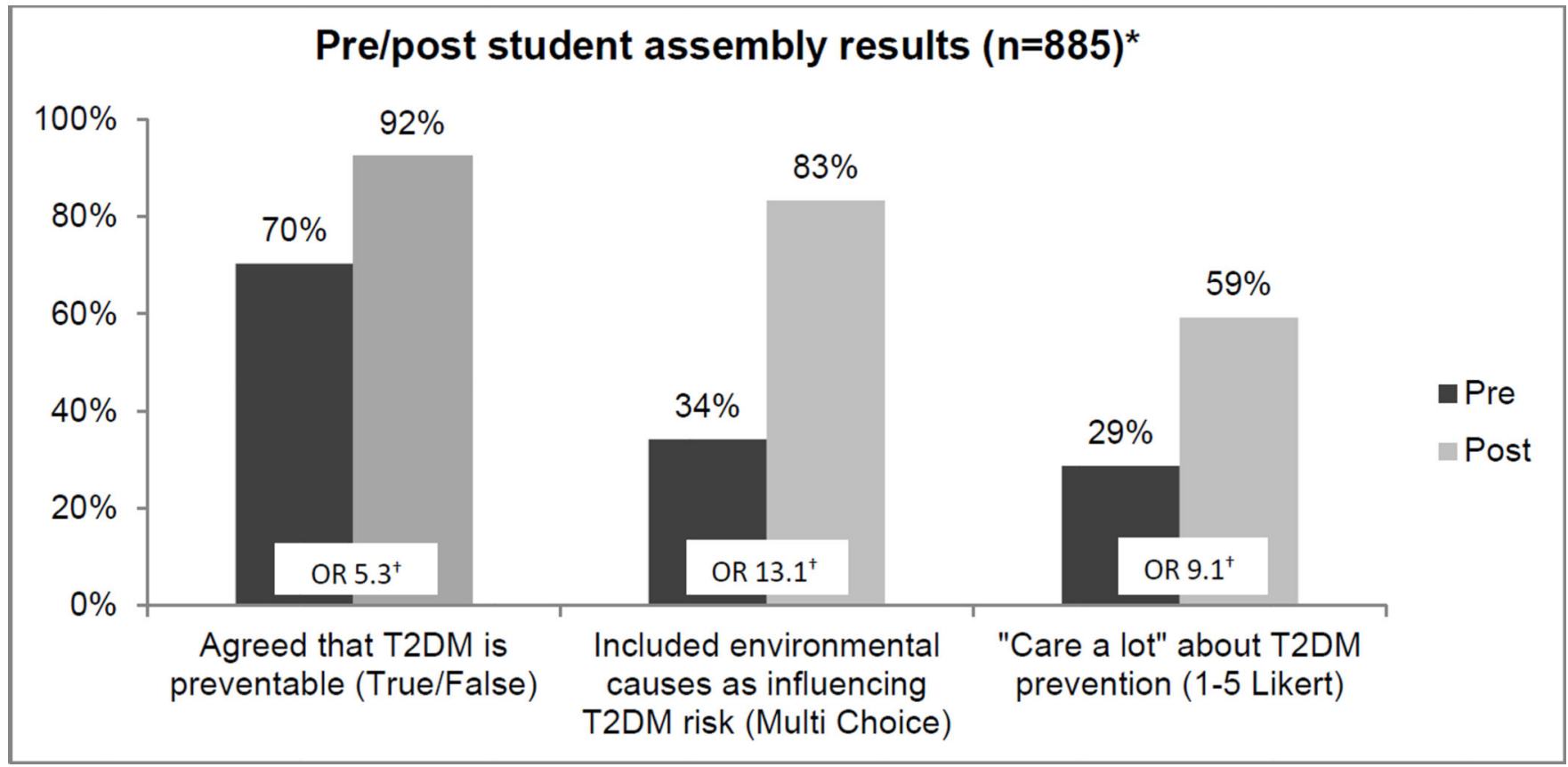

Figure 1.

*McNemar's Chi2 p-values $<0.001$ for each question's pre-post comparison.

$\dagger$ Results of a mixed model adjusted for individual student demographics (Table) and accounting for clustering at the school level. 


\section{Table 1}

Campaign Reach: School assembly demographics.

\begin{tabular}{lcc}
\hline $\begin{array}{l}\text { Assembly Participant Demographics and } \\
\text { Participating School Characteristics }\end{array}$ & $\begin{array}{c}\text { Assembly } \\
\text { Participants } \\
(\mathbf{n = 7 8 1})\end{array}$ & $\begin{array}{c}\text { School } \\
\text { Characteristics } \\
(\mathbf{n = 1 3})^{\dagger}\end{array}$ \\
\hline Female sex, n (\%) & $436(56)$ & - \\
\hline Student enrollment, mean n (range) & - & $982(52,2763)$ \\
\hline Race/Ethnicity, n (\%), and mean \% (range), respectively & $218(28)$ & $32(9,60)$ \\
\hline Hispanic/Latino & $207(27)$ & $33(3,67)$ \\
\hline Asian & $144(18)$ & $20(6,52)$ \\
\hline African American/black & $110(14)$ & $1(0,3)$ \\
\hline Mixed race/multi-ethnic & $53(7)$ & $10(0,40)$ \\
\hline White & $33(4)$ & $2(0,6)$ \\
\hline Pacific Islander & $16(2)$ & $0.5(0,1)$ \\
\hline American Indian & $15.7(15.6,15.8)$ & $66(22,88)$ \\
\hline Age in years, mean (95\% CI) & & \\
\hline Free or reduced lunch rate, mean \% (range) & & \\
\hline
\end{tabular}

For reporting, 104 observations were dropped because of missing demographics data, giving an $88 \%$ response rate.

${ }^{\dagger}$ Data from the California School Accountability Report Card reporting from 2011-2012, found at www.sfusd.edu, http://web.ousd.k12.ca/us or individual school websites. One participating school did not have complete information for the free or reduced lunch rate. 